\title{
HIDDEN IN PLAIN SIGHT: THE DOUBLE STANDARD OF AGING
}

\section{Coral Broughton}

Hidden in Plain Sight is a body of self-portraiture works exploring my own aging within the concept of the invisibility of the aging woman in Western society. My interest in the concept of the veil, real and metaphorical, was the initial idea behind the 'veil of invisibility' as experienced by the aging woman. As a female artist, I am looking at the experiences of older women, with a focus on how women artists respond to the experience of their own aging within their practice.

I consider how the expression of a less visible body is achieved by the tension between figure and ground in the works of Edouard Vulliard, Yayoi Kusama, Kehinde Wiley, René Magritte and Michaël Borremans. Using the patterns of fabrics and wallpapers, these artists created figures that merge into the background in their work or create a textile barrier. I also ask why a work by Auguste Rodin that focused on an aging woman's body was so badly received when it was first exhibited. In contrast, works by Suzy Lake and Cindy Sherman deal with their own aging bodies through confronting images taken throughout their artistic careers.

Articles by feminist theorists Susan Sontag, Michelle Meagher, Griselda Pollock, Jeannette King and Germaine Greer help substantiate my ideas about the 'veil of invisibility'. In her essay "The Double Standard of Aging,"' Sontag discusses social conventions that enable aging men, but destroy women's confidence as they age. In her paper "Against the Invisibility of Old Age: Cindy Sherman, Suzy Lake, and Martha Wilson,"' Meagher discusses the attitudes of three female photographers as they have represented themselves throughout their lengthy careers. In "The Grace of Time: Narrativity, Sexuality and a Visual Encounter in the Virtual Feminist Museum,"'3 Pollock considers classical sculpture, where the body is represented as timeless, ideal form, compared to contemporary methods of observing the aging body.

King's book Discourses of Ageing in Fiction and Feminism:The Invisible Woman 4 proposes that the literature of gender studies contains discrimination toward an invisible generation - that of the post-menopausal woman in Western culture. In The Whole Woman, ${ }^{5}$ Greer focuses on the feminist activists of the 1970s and 19780s who are now moving into old age.

In 2019 the Christchurch Press published an article, "Grey is the New Blonde, Black or Red,"6 in which authorWinnie Salamon concludes: "An unfortunate side-effect of a society that reveres thin, youthful female beauty, is that as women become more accomplished, confident and interesting as they age, qualities that should be a source of empowerment and pride are overshadowed by the one thing they no longer possess: youth." Salamon illuminates the dilemma of the aging woman who experiences shame for no longer retaining her youth, because youth is the currency by which a woman's value is acknowledged in our society. The dividing line between youth and age has generally been that between the reproductive and post-reproductive years. ${ }^{7}$

We are unable to talk about the double standard of aging without comparing the female struggle to the situation of our male equivalents. As Sontag notes in "The Double Standard of Aging," society is much more permissive about aging in men than in women, where men are allowed to age without penalty in ways that women are not. ${ }^{8}$ As men age their social value depends more on what they do than how they look. In recent decades men have been 
much more aware of taking care of their body and face, but it is less about disguising the body, as in the female reality. Men do not disguise their faces, apart from adjusting their facial hair. The male face is seen as something that doesn't need tampering with, where aging is taken as a sign of character, where scars and lines form a map of life experiences and boys look forward to manhood. By contrast, a woman must remain as much like a girl as she can throughout her adult life. Sontag says:

The single standard of aging for women dictates that they must go on having clear skin. Every wrinkle, every line, every gray hair is a defeat. No wonder that no boy minds becoming a man, while even the passage from girlhood to early womanhood is experienced by many women as their downfall, for all women are trained to continue wanting to look like girls. ${ }^{9}$

Greer concurs that women keeping their girlish looks as they age is an unobtainable goal, a goal for which women are set up to fail. ${ }^{10}$ Here lies the difference between the sexes: it is totally unreasonable to expect women to keep the flawless body of a girl well into old age. The accepted definition of femininity includes a slim, unlined, hairless body with soft, smooth skin, where women have become illusionists, seeking to conserve and disguise their bodies to maintain this image for as long as possible. One can point to many beautiful older women - but their beauty is dependent on how long they can retain their appearance of youth, because what makes these women appear beautiful to us is that they do not look their real age!" Sontag's argument is that although both genders experience the ordeal of aging, for men the process is less judgemental and emotionally charged than it is for women, who feel immense pressure to maintain their appearance. As Sontag puts it:

The body of an old woman, unlike that of an old man, is always understood as a body that can no longer be shown, offered, and unveiled... Aging in women is a process of becoming obscene sexually, for the flabby bosom, wrinkled neck, spotted hands, thinning white hair, waistless torso, and veined legs of an old woman are felt to be obscene. ${ }^{12}$

Although Sontag raised awareness of the double standard of aging, it was Meagher three decades later who first addressed the visible and invisibility argument. In "Against the Invisibility of Old Age," she argued that the invisibility of the aging woman has not been addressed, in terms of being taught or acknowledged within academic feminism, in order to understand the impact of power relations and social inequalities that women face as they age. ${ }^{13}$ Although there have been many gains for women through feminism, the field of gender studies has largely ignored issues affecting older women. Meagher argues that the key concerns of the feminist movement have been structured around young women in terms of issues such as employment, child-care, birth control and abortion. ${ }^{14}$

One of the first question I get asked when meeting new people is, "Do you have any grandchildren?" More often than not, my husband is asked, "What do you do?" I feel it is important for women to become aware of this double standard where such questions, which reflect unspoken societal rules, subtly change the power structures between men and women. Women are taught early on to keep old age at bay by investing emotional energy and money into cosmetics, clothes, fashion literature, personal grooming, diets, hairdressers and plastic surgeons. For Greer, women buy into this fakeness by acknowledging that the aging body needs work to keep it looking young, and as a result they put themselves at the mercy of the manufacturers. ${ }^{15}$

Nevertheless, as women work hard at staying youthful and eventually lose the ability to hold back aging, they are perceived as having less value. Meagher observes that in order to appeal to baby boomers, the 'old' people in advertising are actually not old at all - rather, they are young and vibrant. These actors are used as symbolic gestures in the representation of the elderly, having the markers of age, such as grey hair and crows-feet, but lacking the reality. ${ }^{16}$ Consequently, such marketing gives the conflicted message that old age is okay, but it is not okay to look or act old.

Meagher references Marge Piercy's poem "I met a woman who wasn't there,"'17 where Piercy describes a common sensation experienced by midlife women, the transition from visibility to invisibility: "The CIA should hire as spies/ 
only women over fifty, because/we are the truly invisible." Piercy identifies not just the invisibility that the aging woman experiences, but the repulsion an old woman's body evokes. The poet broaches the idea of elderly women who have followed the procedures to keep old age at bay, and still become invisible anyway, noting cynically that women over 50 should be chosen as spies as they are truly invisible.

In contrast, in "The Grace of Time," Pollock argues that in the history of Western art, "old women are few and far between and those who are represented exist to terrify." ${ }^{18}$ One of Pollock's witches and hags is Rodin's sculpture She Who Was Once the Helmet-Maker's Beautiful Wife. ${ }^{19}$ Rodin was fascinated by the inevitable decline of the human body, perceiving the physical changes that occurred not as ugliness, but rather as adding character and personality. The sculpture caused consternation in Paris when it was exhibited there; it was considered that the markers of age were not desirable, nor should they be on public display. As "Petronius Arbiter" wrote in 1916:

this is a degenerate work of art because no woman is ever beautiful when in a state of decay. And in such decay as here represented, she is repellent. No single aesthetic or social excuse can be found for making of this art atrocity, doubly none for exhibiting it. ... this work by Rodin has shocked the normal public, still shocks it and always will shock it, because it is intellectually monstrous and spiritually degenerate ... ${ }^{20}$

The phrase "the male gaze" describes how women have been looked at throughout time through the eyes of the heterosexual male. Filmmaker Laura Mulvey coined the phrase in 1975 in her essay "Visual Pleasure and Narrative Cinema."2l Although its theoretical origins were in film, "the male gaze" refers more broadly to how women are depicted in the visual arts, film, television, advertising and literature. Women are regularly presented, from a masculine perspective, as sexual objects for the pleasure of the male viewer. "The male gaze" is a sexualised way of looking that empowers men and objectifies women. It positions the woman visually as an 'object' of heterosexual male desire, where her feelings, thoughts and her own sexual drives are less important than those of the male viewer. In terms of the aging woman, however, the gaze is absent as she is not an object nor even a subject - she is invisible.

Meagher cites Greer, who asserts that the freedom that comes from an older woman's invisibility is "a desirable condition" where she can live outside of the gaze. ${ }^{22}$ There are no expectations of a sexual nature, as she is not even placed in the line of vision - she is visually passed over and not worth looking at. In "I met a woman who wasn't there," Piercy identifies elderly women as not even standing in the line of sight. In our culture, where beauty equals youth, it is understandable how the older woman is overlooked. One reads about this phenomenon, but when it is experienced first-hand it really is surprising, bewildering and also weirdly liberating.

With my current interest in patterns in juxtaposition to figures, I examined the work of artists Edouard Vuillard ${ }^{23}$, Yayoi Kusama ${ }^{24}$ and Kehinde Wiley ${ }^{25}$ with reference to women in domestic settings, with the emphasis on interiors and fabrics. ${ }^{26}$ I focused on the placement of the figure in relation to her surroundings, ${ }^{27}$ asking how much of the figure was visible in relation to the heavy patterning evident in the backgrounds. I was interested in the notion of the body being immersed into the ground, or being covered by it. I have referenced these explorations in my current body of work.

In Magritte's work, The Lovers, ${ }^{28}$ a barrier of fabric prevents an intimate embrace between two lovers, transforming an act of passion into one of isolation and frustration..$^{29}$ The couple are unable to effectively communicate or touch, the cloth keeping the two figures apart and creating an air of mystery and intrigue. Michaël Borremans' work also conveys strange notions of attraction and intrigue in his staged portraits of females totally enshrouded in bodysuits. ${ }^{30}$ Once again, I used these concepts and techniques in the early development of my own work.

In "The Invisible Woman," Janette King discusses the drawing of the demarcation line around fertility: "Since a woman's value has historically been determined by her ability to produce children, her beauty, sexuality and worth are all in direct correlation to her fertility, and therefore to her youth. The loss of youth in Western culture amounts to the loss of identity." ${ }^{\prime \prime}$ 


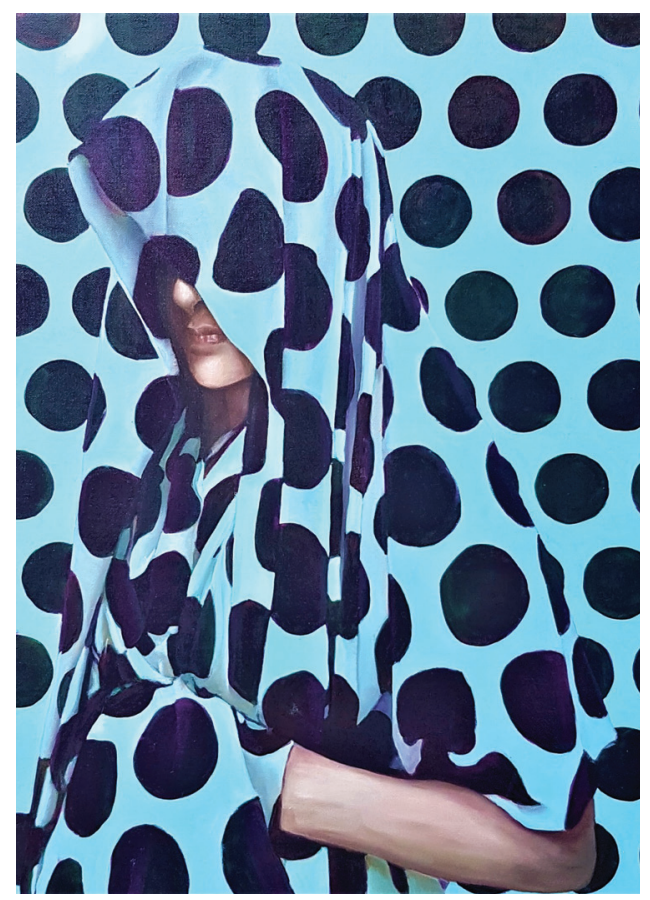

Figure I. Coral Broughton, Lara, 2019, oil on canvas.

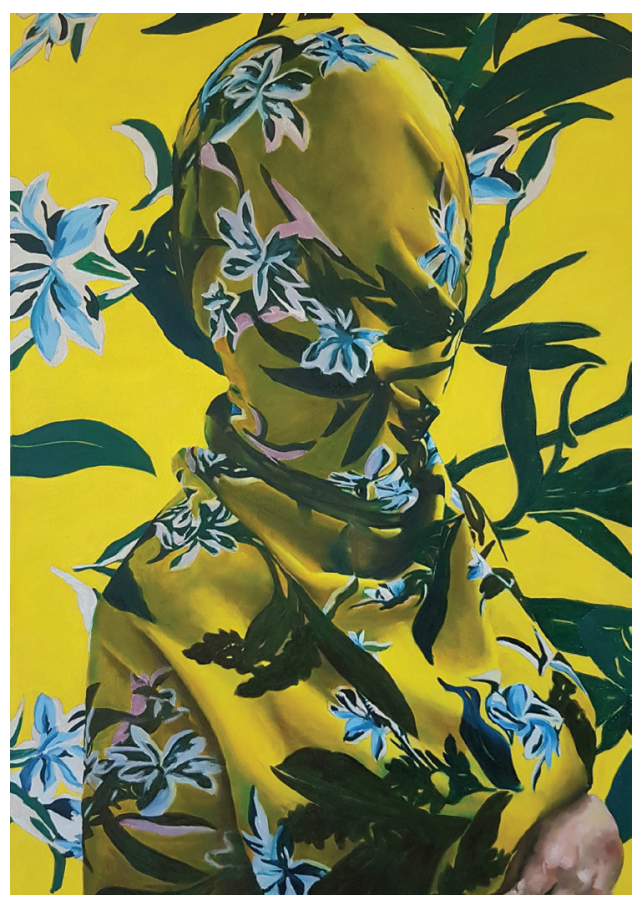

Figure 2. Coral Broughton, Hidden in Plain Sight, 2019 , oil on canvas.

I began to focus on painting self-portraits to bring the aging body into focus. When I look in the mirror I can see my aging in the lines, the sagging skin, the extra rolls of fat and the age spots. I feel it in my muscles and in my joints. I have given up shoes with heels, the effort to hold in my stomach, and I am working hard on not caring about how I appear to others. We live in a society in denial about aging; a denial fuelled by an obsession with image and style, with youth and physical beauty, and the illusion that we can keep making ourselves over to hold old age at bay.

I wanted to utilise my ageing body as one that reveals a history of childbearing and operations, a body which implies a narrative of time. Because photography can capture honest and raw images, I studied the work of contemporary photographers such as Suzy Lake and Cindy Sherman, who dare us to look and stare. It is acceptable to be fascinated by these photos - so, is there a female gaze? Mulvey argues that there is no direct female equivalent of the male gaze. ${ }^{32}$ The male gaze creates a power imbalance and supports a patriarchal society. For this reason, the female gaze cannot be said to resemble the male gaze.

Sherman's images represent what could be called successful aging, but also represent women who have failed to measure up. What emerges from these photographs is the futility of the struggle to hold back the years. Even if you feel pity or embarrassment for her subjects, all women can probably relate to and empathise with them on some level..$^{33}$ These works are seeking to show the struggle that some women face in a culture that is obsessed with reversing the signs of time.

In 2014, at the age of 67, Suzy Lake produced a series titled Beauty at a Proper Distance, which takes an unflinching look at aging and the concept of beauty in a set of close-up shots. These cropped images of her own face display a total lack of vanity, showing wrinkles, blemishes, stained teeth and facial hair. ${ }^{34}$ 
Sherman and Lake, who are in their 60s and 70s respectively, are keenly aware of their own bodies' shifting relationship to a culture that objectifies youthful bodies. What makes these two artists relevant to my own work is their commitment to exploring self in relation to others, but also questions of gender and identity. Although we are not all obsessed with the desire to stay young, resistance is frequently interpreted as defiance or failure.

A pivotal moment arose in my practice when I picked up some large, square brushes and used turps-diluted paint to set up some sort of colour field on large supports. I was using old, pre-used canvas with a history that got accidently caught up in my current work - a situation which I feel worked to my advantage by creating a history beneath my work. By thinning the paint with turps initially, then lean medium, I could work on multiple pieces simultaneously. With a fast-drying time of a day or two, I was able to build up the layers slowly, without my usual tendency to overwork the pieces (Figure 3). Once a layer had been applied, I often wiped it back with a cloth or blotted the paint with paper to achieve greater transparency. This was not done uniformly but only where I wanted to expose more of the substrate layers, creating an interesting play between figure and field (Figure 4).

I worked with multiple transparent layers to suggest a journey of time. These layers also referenced interior patterns, whether curtains and soft furnishing or venetian blinds, door frames or furniture or shadows, referring to perspective. Although I turned to the colour wheel to examine complementary colours for the paint chosen, in the end it was mainly a question of what sat well in terms of temperature and tone (Figure 5). I realised that the 'process of doing' effected my decisions in the studio in terms of the choices I made (Figure 6).

My visual diary, used as a chronological journal, was invaluable in revealing pivotal changes in direction. When reviewing hours of studio practice, documented in two or three A3 pages in my workbook, ${ }^{35}$ it became obvious where the key moments were in the painting process. More often than not, these moments occurred after I proceeded to 'finish' the work, and found that in fact I had been overworking and losing some spontaneity in the work. In some respects, failure created a favourable environment which enabled me to achieve more successful outcomes that I had anticipated.

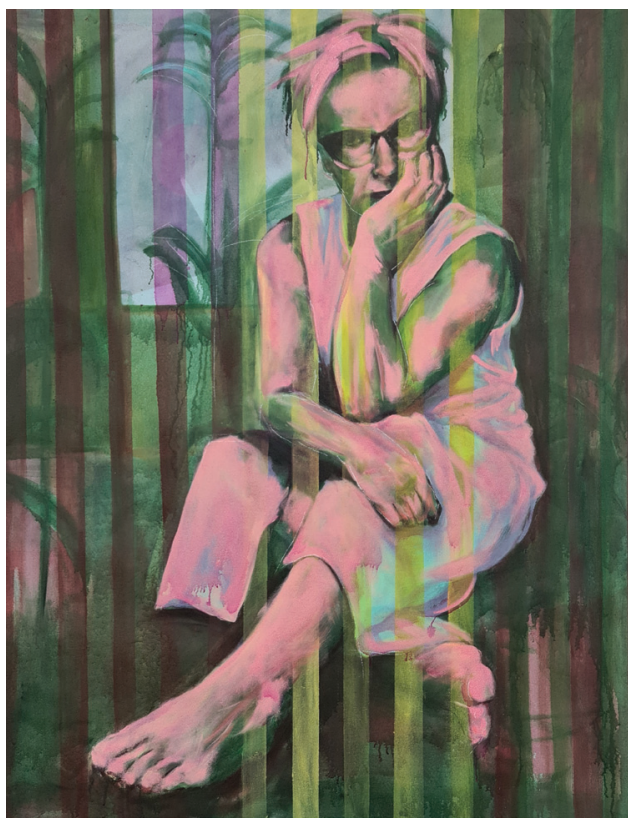

Figure 3. Coral Broughton, Dust on the Wind, 2020, oil on canvas on board, $1500 \times 1200 \mathrm{~mm}$.

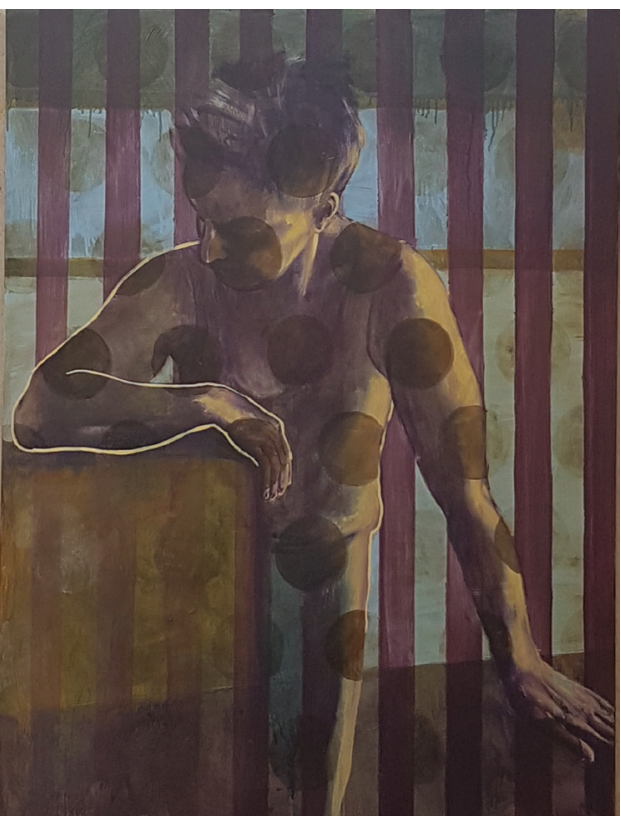

Figure 4. Coral Broughton, Through Check Points, 2020, oil on board, $1200 \times 900 \mathrm{~mm}$. 


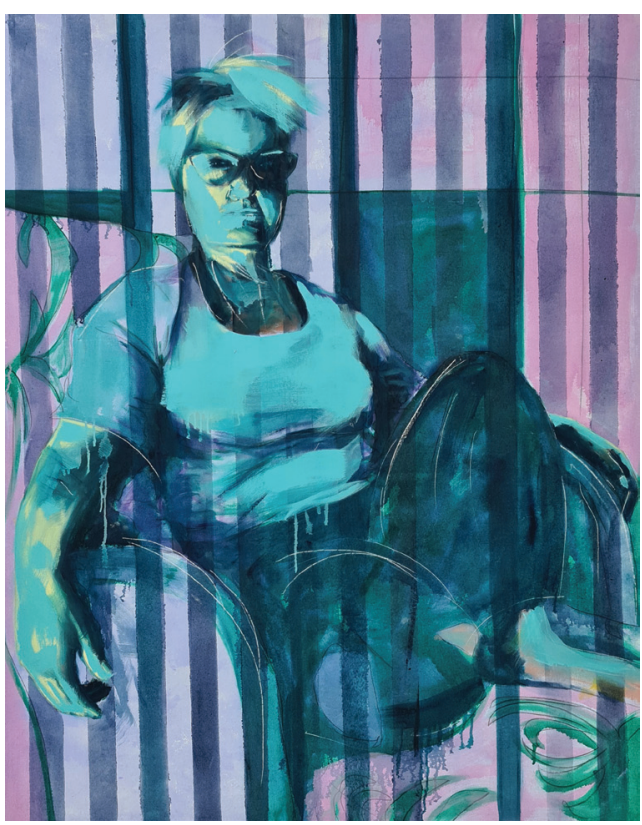

Figure 5. Coral Broughton, Only Your Cats Will Listen, 2020, oil on canvas on board, $1500 \times 1200 \mathrm{~mm}$.

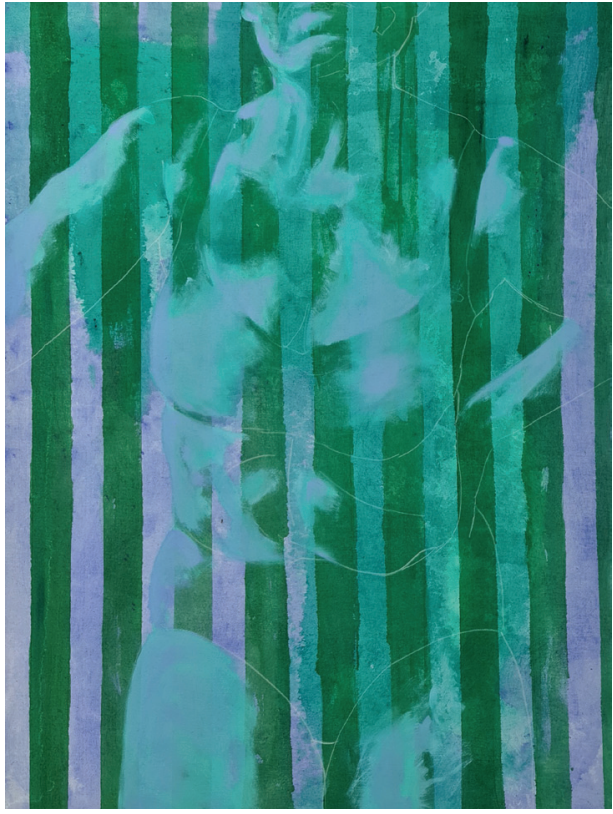

Figure 6. Coral Broughton, Through Spider Webs, 2020, oil on canvas on board, $1200 \times 900 \mathrm{~mm}$.

\section{CONCLUSION}

In conclusion, the veil is lifting in terms of revealing some of the issues that older women face as they age in our Western culture. As a female artist, I am looking at how women have been represented, or not represented, in the art historical canon, and I am also considering historical and contemporary artists who have addressed the aging process and are continuing to do so. Female artists who are producing work that is raw and honest confront the aging issue and bring some awareness to the cultural anomalies between men and woman in terms of aging.

Sontag says women should tell the truth and allow their faces to age and show the experiences of lives lived, instead of grasping for youth well beyond its expiry date. ${ }^{36}$ Meagher looks at the work of female artists who have documented their careers through self-representation, the results of which are viewed through a time perspective. ${ }^{37}$ These artists have made advances in exposing our conventional cultural narrative through images that show the process of aging as a contemporary art form, offering not just images, but an invitation to view these images of aging women in a new way. They invite visual encounters that are reflective and have moved beyond the male gaze, but still acknowledging the need for looking and being looked at. ${ }^{38}$ Meagher suggests that our relationship to the gaze is constantly changing and being re-evaluated.

In a culture where beauty and even feminism is tied to youth, there comes a time when no matter how healthy and well-groomed women are, they realise that they are being overlooked. Sometimes, this reaction is greeted with relief and a sense of freedom as the pressure to 'dress to impress' is removed. Greer sees aging as an opportunity for re-definition - a space where aging is a desirable condition marked by indifference, allowing for freedom to live outside the gaze. ${ }^{39}$ 
The core of female self-representational art is the artist's body. Her art represents the embodied experience of the artist - her family, sexuality, relationships, childhood experiences and personal traumas, plus the way her culture has shaped her and her response to its oppression. These women seek not only to be ambitious - and not just for themselves - through family or relationships, but to tell the truth through a face that tells a story of time.

My project Hidden in Plain Sight invites new ways of looking at older women, encouraging us to look in a more reflective manner. We must embrace aging as part of our visual culture and endeavour to pull older women out from under the veil of cultural invisibility.

Coral Broughton BFA (llam School of Art, University of Canterbury) MVA (Dunedin School of Art, Otago Polytechnic) DipTchg (University of Otago), is an artist who confronts the female aging process through her self-portraiture works. She currently runs an art school in Rangiora and exhibits regularly.

I Susan Sontag, The Double Standard of Aging (Toronto, ON:Women's Kit, 1972), 285-94.

2 Michelle Meagher, "Against the Invisibility of Old Age: Cindy Sherman, Suzy Lake, and Martha Wilson," Feminist Studies, 40: I (2014), I0I-43.

3 Grizelda Pollock, "The Grace of Time: Narrativity, Sexuality and a Visual Encounter in the Virtual Feminist Museum," Art History, 26:2 (2003), 174-213.

4 Jeanette King, Discourses of Ageing in Fiction and Feminism: The Invisible Woman (New York, Palgrave Macmillan, 20I3).

5 Germaine Greer, The Whole Woman (London, UK: Black Swan, 2007).

6 Winnie Salamon, "Grey Is the New Blonde, Black or Red," The Press [Christchurch, NZ], 6 February 20 I 9, BI.

7 Kathleen Woodward, "Performing Age, Performing Gender," NWSA Journal, I8:I (2006), I 68.

8 Sontag, Double Standard, 286.

9 Ibid., 290.

10 Greer, Whole Woman, ch. 2,7. 
Ibid., ch. 2, I.

12 Sontag, Double Standard, 285.

13 Meagher, "Invisibility," 103.

14 Ibid., 102.

15 Greer, Whole Woman, ch. 3, 2.

16 Meagher, "Invisibility," 104.

Marge Piercy, "I met a woman who wasn't there," NWSA Journal, I 8:I (2006), I-2.

18 Pollock, "Grace of Time," 193.

19 "Caira / She Who Was Once the Helmet-Maker's Beautiful Wife | Auguste Rodin / François Villon, I 884-85," http://www. cocosse-journal.org/2014/0I/auguste-rodin-old-courtesan-francois.html.

20 Petronius Arbiter, “A Degenerate Work of Art: 'The Helmet-Maker's Wife' by Auguste Rodin," The Art World, I:2 (November 1916), 125-6.

21 2l Laura Mulvey, "Visual Pleasure and Narrative Cinema," in Feminist Film Theory: A Reader, ed. Sue Thornham (Edinburgh: Edinburgh University Press, 1999), 58-69.

22 Meagher, "Invisibility," 130.

23 Wikipedia, “The Seamstress (painting)," https://en.wikipedia.org/wiki/The_Seamstress_(painting).

24 Kelly Richman-Abdou, "How Pumpkins Have Inspired Yayoi Kusama's Avant-garde Art for Decades," My Modern Met, I4 October 2019, https://mymodernmet.com/yayoi-kusama-pumpkins/.

25 Kehinde Wiley, "Shantavia Beale II, 20I2," https://www.artsy.net/artwork/kehinde-wiley-shantavia-beale-ii; Krista Thompson, "The Sound of Light: Reflections on Art History in the Visual Culture of Hip-Hop," The Art Bulletin, $91: 4$ (2009), 48I-505, at 482.

26 David Carrier,"The Beauty of Henri Matisse," Journal of Aesthetic Education, 38:2 (2004), 80-87, at 81.

27 J.C., "A Seamstress by Edouard Vuillard," Bulletin (St. Louis Art Museum), 12:2 (1976), 21 -3.

28 "René Magritte, The Lovers, Paris 1928," https://www.moma.org/collection/works/79933.

29 Worth Hawes, "Attempting The Impossible: Deciphering the Devastating Terms of Magritte and Psychoanalysis," Soundings: An Interdisciplinary Journal, 84:1-2 (2001), 8-30, at I6.

30 "Michaël Borremans, Mercy, 20 16," https://artbasel.com/catalog/artwork/49866/Michaël-Borremans-Mercy.

31 King, Discourses of Ageing, 221.

32 Mulvey, "Visual Pleasure," 62.

33 Hyunjee Lee, "Cindy Sherman's New Show Examines Rich Women and Age-shaming," The Cut, 17 April 2017, https://www. thecut.com/2017/04/cindy-sherman-society-portraits-mnuchin-gallery.html.

34 Suzy Lake, "Beauty at a Proper Distance / In Song 200 I-2," https://www.suzylake.ca/beauty-at-a-proper-distance\# I.

35 Carole Gray and Julian Malins, Visualising Research:A Guide to the Research Process in Art and Design (Aldershot, UK: Ashgate Publishing, 2004).

36 Sontag, Double Standard, 294.

37 Meagher, "Invisibility," I I 2.

38 Ibid., 143.

39 Greer, Whole Woman, ch. 3, I- I I. 